Correction

\title{
Correction: Ding, X.; Liu, G.; Du, M.; Guo, H.; Qiao, H. and Gerada, C. Development of an Axial Flux MEMS BLDC Micromotor with Increased Efficiency and Power Density. Energies 2015, 8, 6608-6626
}

\author{
Xiaofeng Ding ${ }^{1}$, Guanliang Liu ${ }^{1,+}$, Min Du ${ }^{1,+}$, Hong Guo ${ }^{1}$, Hao Qian ${ }^{1, *}$ and \\ Christopher Gerada ${ }^{2}$
}

Received: 22 December 2015; Accepted: 19 January 2016; Published: 21 January 2016

1 School of Automation Science and Electrical Engineering, Beihang University, Beijing 100191, China; dingxiaofeng@buaa.edu.cn (X.D.); liu_guanliang@163.com (G.L.); dumin0201@gmail.com (M.D.); guohong@buaa.edu.cn (H.G.)

2 Department of Electrical and Electronic Engineering, the University of Nottingham, Nottingham NG7 2RD, UK; Chris.Gerada@nottingham.ac.uk

* Correspondence: qianhao@buaa.edu.cn; Tel./Fax: +86-10-8233-8455

+ These authors contributed equally to this work.

We wish to make the following change to the published paper [1]. The name of the corresponding author should be "Hao Qian" instead of "Hao Qiao". We apologize to readers for any inconvenience caused by this changes.

\section{Reference}

1. Ding, X.; Liu, G.; Du, M.; Guo, H.; Qiao, H.; Gerada, C. Development of an Axial Flux MEMS BLDC Micromotor with Increased Efficiency and Power Density. Energies 2015, 8, 6608-6626. [CrossRef]

(C) 2016 by the authors; licensee MDPI, Basel, Switzerland. This article is an open access article distributed under the terms and conditions of the Creative Commons by Attribution (CC-BY) license (http:/ / creativecommons.org/licenses/by/4.0/). 